\title{
Relationship between Chakra Energy and Consciousness
}

\author{
DK Chaturvedi* \\ Department of Electrical Engineering, Centre for Consciousness Studies, India \\ *Corresponding author: DK Chaturvedi, Department of Electrical Engineering, Centre for Consciousness Studies, India
}

ARTICLE INFO

Received: 慧 February 20, 2019

Published: 絊 March 01, 2019

Citation: DK Chaturvedi. Relationship between Chakra Energy and Consciousness. Biomed J Sci \& Tech Res 15(3)-2019. BJSTR. MS.ID.002705.

\begin{abstract}
In the Hindu philosophy it is clearly mentioned that the chakra energy in human body is directly related to the human consciousness. The present work deals with the experimental study to validate this fact and prove that the chakra energy is directly related to the human consciousness. The study is performed on 122 people.
\end{abstract}

\section{Introduction}

The ancient Chinese systems, acupuncture [1] and acupressure $[2,3]$, have gained general public acceptance internationally and, to a limited extent, in the main-stream science (e.g. for relief of dental and obstetric pain). These are based, in theory, on the existence of 12 meridians each on the two sides (Total 24 and 365 acupressure points on the limbs. The status of an organ depends on the balance between the meridians. This also indicates body's energy level. However, until recently, the only method available for determining the status of the energy level of the meridians was by physical means or by clinical examination. Over the last 50 years or so the Japanese scientists have developed the quasi-scientific Ryodoraku system [4] in which the electrical resistance of tissues at selected acupressure points in the limbs on two sides, which were also identified in the ancient Chinese systems, is measured by an instrument, developed in Japan, the Electro Meridian Analysis System (MEAD Analyzer) [5]. It uses currents of less the $100 \mu \mathrm{A}$ to determine the local tissue resistance at the acupressure points. As such it is harmless and, in fact, it has been approved for medical application in Japan and Taiwan. This resistance measurement indicates the under-or over-functioning (energy level) of the meridians. From this the status of function of different organs and body's energy level can be measured. According to Ryodoraku theory a disturbance of the balance of the meridians causes disease. This can be restored by acupuncture, acupressure or Ryodoraku therapy. In this paper the chakra energy is measured using MEAD sensors and the study is conducted to correlate the chakra energy and consciousness level of human being.

\section{Proposed Method}

The self-made Sensor have been designed to measures the energy level of human at different energy centers (chakras) of the human body which is directly related to the consciousness level of a person [2]. This setup measures the consciousness level of the workers in industry to show that worker with high consciousness level will perform and gives better outcomes than an employee with low consciousness level which have higher fault rate and low performance. This study will help in promoting and maintaining job efficiency in industry. The study will also help in determining whether the employees needs training and if yes then how much efforts company has to put in. It can also be serving as a partial basis for salary increase, promotion etc. Hence, this study will prove very useful to promote work performance and work safety.

\section{Results and Discussion}

A Pilot study is conducted on 122 people and the results are obtained as shown in Figure 1. The average Energy (Micro Amp current) of different chakras are given below:
a) Eye Center - 106.7
b) Throat Center - 87.6
c) Heart Center - 74.7
d) Navel Center - 66.5

Also, the chakra energy raised during prayer/meditation as shown in Figures 2s \& 3 for 24 hours. 
After morning prayer - 6AM,

After Evening prayer - 7PM and

After taking lecture - 3PM .

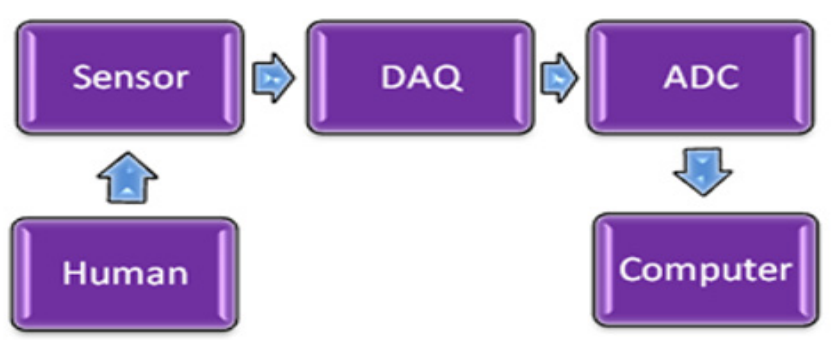

Figure 1: Block diagram of proposed system.

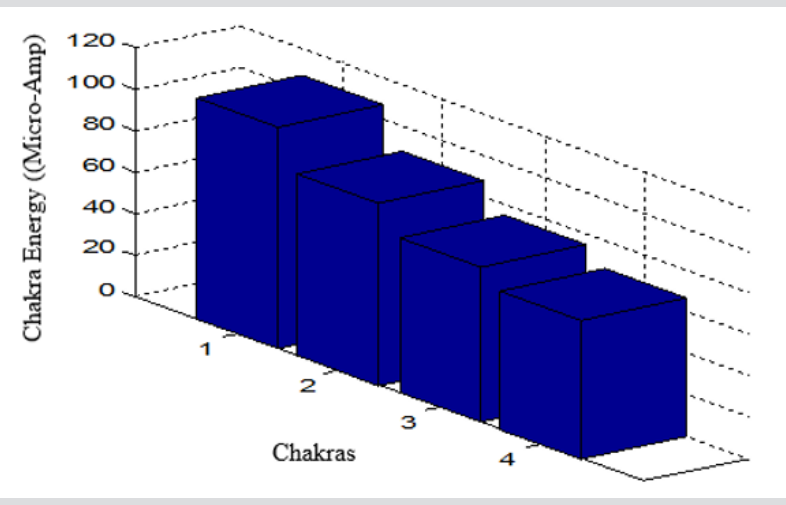

Figure 2: Measurement of Energy Profile using micro Amp current.
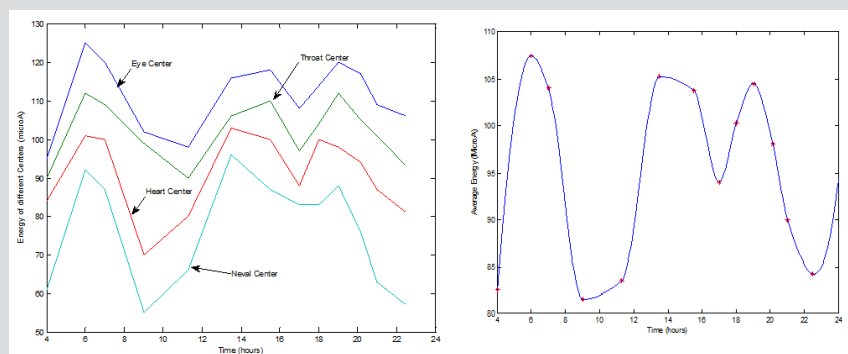

Figure 3: Energy Profile for 24 hours.

a) Different Chakra Energy Variation for 24 hours.

b) Average Energy variation of human being for 24 hours

\section{Conclusion}

The individual consciousness depends on an individual's habits, type of work they perform (e.g. Teaching or solving puzzles etc.), meditation / Prayer etc. It is accepted that the consciousness Level of higher centers (CHAKRAS) are higher than lower centers. In the measurement of chakra energy, we found that highest energy at eye center and lowest at navel center. Hence, it is proved that there a correlation between consciousness and energy distribution profile of Human body. These chakra energies are not constant throughout the day and night, but vary during 24 hours' time. It is also observed that the Chakra energy variation does not cross each (i.e. the lower chakra energy remains lower and higher chakra energy remains higher during these variations).

\section{References}

1. Zhu Bing, Wang Hongcai (2010) Acupuncture therapeutics. In Zhu Bing, Wang Hongcai (Eds.) Singing Dragon, London.

2. Michael Reed Gach (1990) Acupressure's Potent Points: A Self-Care Guide for Common Complaints from A to Z. Bantam Doubleday Dell Publishing Group Inc, United States.

3. Michael Reed Gach, Beth Ann Henning (2004) Acupressure for Emotional Healing: A Self-Care Guide for Trauma, Stress \& Common Emotional Imbalances. Bantam.

4. Hirohisa Oda (1968) Ryodoraku Autonomic Nervous System Therapy, Japan.

5. Health Epoch (2005) Electro Meridian Analysis System (EMAS 2005). 


\section{ISSN: 2574-1241}

DOI: 10.26717/BJSTR.2019.15.002705

DK Chaturvedi. Biomed J Sci \& Tech Res

(C) This work is licensed under Creative

Submission Link: https://biomedres.us/submit-manuscript.php

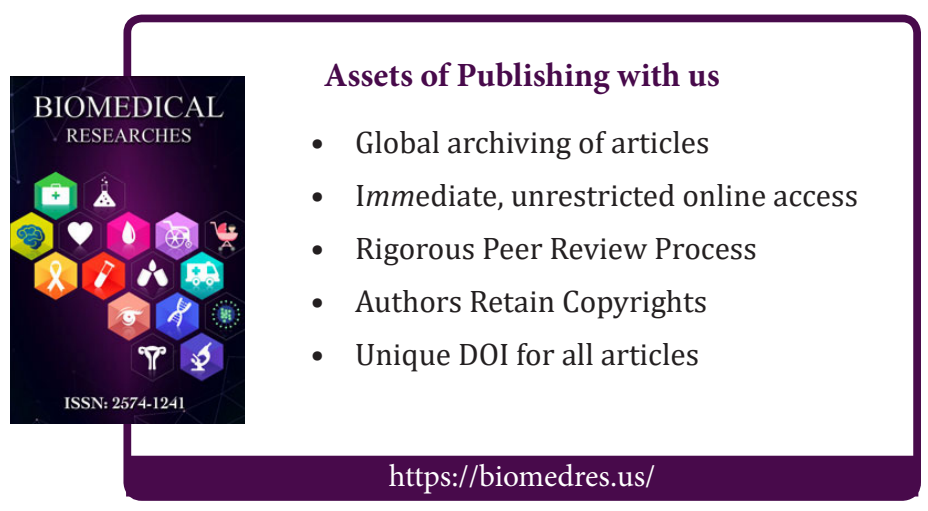

